\title{
NEW MEETING HOTEL
}

The Boston Marriott/Copley Place Is Selected

To Provide Optimal Surroundings For The Annual Meeting

The continuing growth in the membership of the Materials Research Society has dictated a change in our meeting site. For that reason, this year's Annual Meeting will be held at one of Boston's newest and finest hotels, the Boston Marriott/Copley Place.

\section{New Facilities - Traditional Charm}

The Boston Marriott/Copley Place opened its doors May 20 , and offers our Society the very latest in meeting facilities-including facilities for our new Equipment Show-combined with the charm and convenience of downtown Boston. The hotel rises 38 stories above Copley Plaza, with its 18th-century historic sites and its 20thcentury office buildings. It's connected by a skywalk to the Prudential Center, the Hynes Auditorium and Civic Center, and a business/shopping complex with 75 boutiques, specialty shops, and department stores. In the Marriott itself, there are three restaurants, ranging from an oldfashioned delicatessen to an elegant eating place. One of the two lounges features an oyster bar.

\section{Room for Work - And Relaxation}

The Marriott's meeting facilities are exceptional. Symposia of every size can be comfortably accommodated, the general sessions enhanced, and the equipment exhibition most conveniently situated.

At day's end, guest rooms furnished with 18th-century styled furniture, rather than the usual "motel modern" decor, beckon, as do a year-round indoor pool, a health club, exercise equipment, and saunas. The Boston Marriott/Copley Place is only 15 minutes from Logan Airport. It's next to the Massachusetts Turnpike, and directly connected to the Back Bay Transportation Center, with its rail, subway, and bus terminals. Combine this superb location with the outstanding facilities, and the Materials Research Society has the ingredients for the most successful-and enjoyable-Annual Meeting yet.

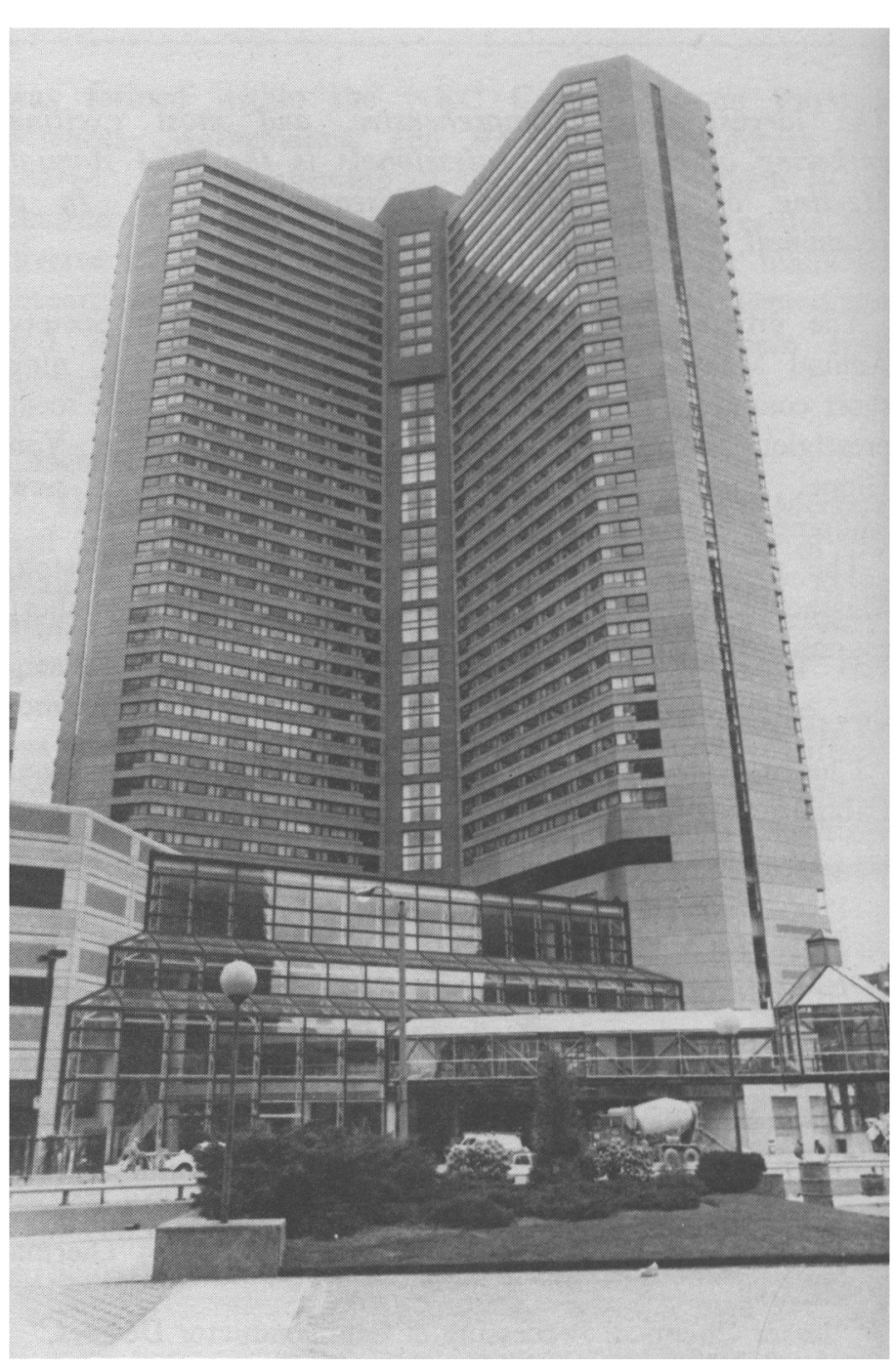

BOSTON MARRIOTT/COPLEY PLACE, rising 38 stories above the heart of the city, has the finest facilities for the expanded 1984 Annual Meeting of the Materials Research Society

\section{CONFERENCE}

\section{ON MATERIALS}

\section{FOR PROCESS INDUSTRIES}

Recent changes in the process industries often require superior materials and techniques, many of which will be explored at the conference on "Advances in Materials Technology for Process Industries' Needs," to be held Oct. 29-31 at the Atlanta Hilton Hotel.
Sponsored by the Federation of Materials Societies and managed by the National Association of Corrosion Engineers, the conference is intended to serve technical managers, developers, designers, and operators in the processing industries, and those involved in selecting materials and preventing corrosion, in addition to the developers or such materials and techniques.

Registration is $\$ 225$ in advance. For information contact:

Dale Miller

National Association of Corrosion Engineers

P.O. Box 218340

Houston, Texas 77218

(713) 492-0535 
Boston

November 26-30

at the

Boston Marriot Hotel Copley Place

Show: November 27-29

Exhibitors (as of 6/5/84)

Acton Research

A G Associates

Air Products and Chemicals

Amplifier Research

ARL

Atomika

Blake Industries

CARBORUNDUM

Cryomagnetics

Cryo Systems

CTI-Cryogenics

Digital Equipment

Dycor Electronics

Eaton/lon Beam Systems

EDAX International

EG\&G ORTEC

EG\&G Princeton Applied Research

Gatan

General lonex

Harshaw/Filtrol

Helionetics

Hitachi Scientific Instruments

Huntington Labs

Innovative Technology

Instrument Technology Ltd

Instruments SA/Riber

International Advanced Materials

Ion Tech Ltd

Janis Research

JEOL/USA

Keithley Instruments

Kevex

Kimball Physics

Klinger Scientific

Lake Shore Cryotronics

Lambda Physik

Laser Science

LeCroy Research Systems

Leitz

LeMont Scientific

Kurt Lesker

Leybold-Heraeus

Lumonics

Microscience

MKS Instruments

Modern Instrumentation Laboratory

National Electrostatics

NESLAB Instruments

Newport

NGS Associates

Nicolet

NSLS

NUCLIDE/AGV

Oriel

\section{Technical Program November 26-30, 1984}

A series of interdisciplinary symposia on topics at the forefront of materials research, ranging from basic research to applications. The goal is to insure that all possible physical, chemical, and engineering insights are considered for the topic under examination. Symposium topics are

\section{A. Energy Beam-Solid Interactions} and Transient Thermal Processing

B. Laser Chemical Processing of Semiconductor Devices

C. Impurity Diffusion and Gettering in Semiconductors

D. Layered Structures, Epitaxy, and Interfaces

E. Catalysis by Solids: Bulk Properties, Surface Properties, and Defects

F. Plasma Synthesis and Etching of Electronic Materials

G. High Temperature Ordered Intermetallic Alloys

H. Hydrogen in Metals: Physics, Metallurgy, and Engineering Approaches

I. Intercalated Graphite

J. The Potential for Very High Strength Cement-Based Materials

K. Advanced Techniques for the Characterization of Defects in Solids

L. Electronic Packaging Materials Science

M. Coal Combustion and

Conversion Wastes:

Characterization, Utilization, and Disposal

N. Scientific Basis for Nuclear Waste Management

O. Alloy Phase Diagrams

P. Fractal Aspects of Materials: Metal Catalyst Surfaces, Powders and Aggregates

$X$. Frontiers in Materials Science (invided papers only)

For meeting \& short course information, contact: John B. Ballance,

Executive Director

Materials Research Society

9800 McKnight Road,

Suite 327

Pittsburgh, PA 15237

Telephone (412) 367-3003

\section{Short Courses}

November 30-December 1

A program of one- and two-day short courses will complement the science and technology presented in the technical symposia and provide an introduction to other current technologies. Short course topics are:

$\star$ Surface and Thin Film Analysis

*Ion Implantation into Metals

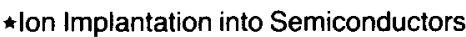

$\star$ Liquid Phase Epitaxy Techniques

$\star$ Modern Analytical Techniques in Corrosion

Research

*Molecular Beam Epitaxy

$\star$ Chemical Vapor Deposition

$\star$ Vacuum Technology

« Pumping Hazardous Gases

Exhibitors Con't (as of 6/5/84)

Oxford Instruments

Perkin Elmer/Physical Electronics

Perkin Elmer/Vacuum Products

Philips Electronic Instruments

Photochemical Research

Associates

Physicon

Questek

Rigaku/USA

Rudolph Research

Scintag

Semiconductor

Processing

S.I.C./McPherson

L.M. Simard

Southbay

Technology

SPECTRAMASS

Spex Industries

Spire

Structure Probe

Surface Science Laboratories

Tachisto

Thermionics Laboratory

Tracor Northern

UHV Instruments

Vacuum Science Workshop

Veeco

VG Instruments

Show information:

Ed Tober, MRS Show Manager

American Institute of Physics

335 East 45th Street

New York, NY 10017

Telephone (212) 661-9404 